REVES - Revista Relações Sociais, Vol. 04 N. 03 (2021)

https://periodicos.ufv.br/ojs/reves

doi: 10.18540/revesvl4iss3pp12739-01-09e

OPEN ACCESS - elSSN: 2595-4490

\title{
Identidade territorial: um estudo de caso de um migrante na cidade de São João do Baliza-RR
}

Territorial identity: a case study of a migrant in the city of São João do Baliza-RR

José Domingos Alves dos Santos ${ }^{1}$, Lucenir Lucena Ferreira² e Sergio Luiz Lopes ${ }^{3}$

${ }^{1}$ Universidade Estadual de Roraima, Programa de Pós-Graduação em Educação (PPGE UERR/IFRR), Brasil, E-mail: santdomii@hotmail.com, ORCID: https://orcid.org/0000-0002-7026-8286

2 Universidade Estadual de Roraima, Programa de Pós-Graduação em Educação (PPGE UERR/IFRR), Brasil, E-mail: lucenir.ferreira@uerr.edu.br, ORCID: https://orcid.org/0000-0001-9151-7598

${ }^{3}$ Universidade Federal de Roraima (UFRR), Curso de Educação do Campo, Mestrado em Educação da UERR/IFRR, Brasil, E-mail: serlupez@yahoo.com.br, ORCID: https://orcid.org/0000-0001-8802-7897

ARTICLE INFO

Article history:

Received 2021-06-21

Accepted 2021-08-02

Available online 2021-08-02
Palavras-chave: Cultura. Deslocamentos. Identidade Territorial.

Keywords: Culture. Displacements. Territorial identity.

RESUMO. O presente relato descreve a trajetória de um migrante nordestino, que chega em Roraima na década de 80 . A escolha pela temática se fundamenta em dois momentos importantes: o primeiro diz respeito as lembranças da infância, da cultura, algo muito forte na minha vida; o segundo ocorreu quando, durante as aulas do curso de mestrado tomei consciência da historicidade e identidade que construí ao longo deste período mediatizado pelas relações sociais dos meios viventes, sentindo a necessidade de registrar estas ressignificações das identidades territoriais. A cada instância vivida houve um crescimento, com agregação de novos valores culturais, onde sofreu-se influencia e também influenciou. A pesquisa narrativa propõe revelar as memórias e histórias de um homem de 51 anos, que chegou ao estado de Roraima aos 18 anos, oriundo do Estado de Goiás. Concluímos que a escola é importante para. O desenvolvimento do processo de conhecimento sistemático que norteia a vida do sujeito, durante sua existência, oportunizando uma melhor qualidade de vida e ações mais conscientes acerca dos problemas que vivenciam.

ABSTRACT. This report describes the trajectory of a northeastern migrant who arrived in Roraima in the 1980s. The choice for the theme is based on two important moments: the first was related to the memories of childhood, of culture, something very strong in my life; the second occurred when, during the master's course classes, I became aware of the historicity and identity that I built throughout this period mediated by the social relations of living environments, feeling the need to register these re- 
significations of territorial identities. At each instance lived there was a growth, with the aggregation of new cultural values, where it was influenced and also influenced. The narrative research proposes to reveal the memories and stories of a 51-year-old man, who arrived in the state of Roraima at the age of 18, from the state of Goiás. We conclude that school is important for. The development of the systematic knowledge process that guides the subjects' lives during their existence, providing opportunities for a better quality of life and more conscious actions about the problems they experience.

\section{Introdução}

Ao retratarmos nossas memórias necessitamos falar sobre quem somos, falar sobre o que somos e como nossa identidade foi construída requer um resgate histórico de nossas memórias. A prática de escrever sobre si expõe a necessidade de refletir sobre a experiência pessoal e profissional buscando entender as trajetórias que vão delineando o ofício docente.

A proposta do trabalho, foi a produção autobiográfica, através de relato oral e escrito das experiências vividas em uma temporalidade da primeira infância até os dias atuais, como discente no mestrado.

Vários foram os desafios enfrentados pelo percurso, pois a migração, ainda na infância, foi uma decisão familiar, que impactou diretamente na formação cultural e profissional até o presente momento. Essa mudança cultural, que adquirimos no processo migratório, essa busca da terra para produção e manutenção da família, gerava uma perspectiva para a melhoria de vida, foi um processo que possibilitou uma estabilidade profissional, o ensino formal na escola pública fez uma diferença na minha vida, devo muito a este sistema, os anos de escola me possibilitou deixar os difíceis anos de trabalho na lavoura, no sol quente, oportunizando uma vida mais digna na condição de servidor público na área da educação.

Desse modo, essa experiência adquirida ao longo da vida, resulta em uma análise da trajetória, perpassa aprendizagens adquiridas ao longo do caminho e superação de muitas dificuldades, pois quando uma família se propõe a mudar de região, tal decisão está atrelada a novas perspectivas de vida, em especial nos aspectos social, político e econômico.

[...] construir sentido a partir das experiências pessoalmente vividas [...] A entrada pelo pessoal constitui o que é chamado de literatura intima [...] diários íntimos, cartas e correspondências [...] a entrada temporal é também rica de denominações: genealogia, memória, lembranças, diários de viagens [...] (PINEAU, 2006, p. 331) 


\section{Metodologia}

A pesquisa autobiográfica utiliza diversas fontes: Histórias de Vida, Biografias, Autobiografias, Memoriais, usando como instrumentos de coleta de dados as narrativas ou a história oral, fotos, vídeos, filmes, diários, documentos em geral, os quais dependem da memória ${ }^{1}$. Esta, é o componente essencial na característica do (a) narrado $\mathrm{r}$ (a) com que o pesquisador trabalha para poder (re) construir elementos de análise que possam auxiliá-lo na compreensão de determinado objeto de estudo.

Neste contexto, o pesquisador adota uma tradição em pesquisa que valoriza a realidade social multifacetária, socialmente construída por seres humanos que vivenciam a experiência de modo holístico e integrado, em que as pessoas estão em constante processo de autoconhecimento, onde o pesquisador não pretende estabelecer generalizações estatísticas, mas, sim, compreender o fenômeno.

A pesquisa de cunho qualitativa e narrativa propõem revelar as memórias e histórias de um homem de 51 anos, que chegou ao estado de Roraima aos 18 anos, oriundo do Estado de Goiás.

\section{Trajetória Vivida}

As pessoas vivem histórias e no contar dessas histórias se reafirmam. Modificam-se e criam novas histórias. As histórias vividas e contadas educam a nós mesmos e aos outros, incluindo os jovens e os recém pesquisadores em suas comunidades. (CLANDININ e CONNELLY, 2011, p. 27)

Nascido aos 15 de junho de 1969, num vilarejo pertencente ao município de Codó, no interior do maranhão, seus genitores são agricultores semianalfabetos. Aos sete anos de idade trabalhava na roça, na agricultura de subsistência com o pai, onde trabalhou até os 21 anos. Nos primeiros anos, até os doze anos, não tinha acesso ao ensino formal, vivia em um lugar isolado, distante de outras pessoas, onde políticas públicas de educação eram inexistentes, pois não havia nenhuma modalidade de ensino.

Com a separação dos pais biológicos, o mesmo foi morar com o pai na mesma região, e passou a conviver com a madrasta que tinha, nos anos sessenta, estudado

\footnotetext{
${ }^{1}$ Memória será trabalhada [...] como memória individual, tanto do narrador, como do pesquisador, intrínseca às relações vivenciais - sociais e culturais - e por elas informada/significada/ressignificada. Outras compreensões sobre a memória, como memória coletiva e memória pública (ver: Halbwachs, 1976).
} 
até a quarta série. A pedido da madrasta, o pai comprou a cartilha chamada "Caminho Suave" e a tabuada, para que o mesmo aprendesse a realizar as operações básicas de matemática e fosse alfabetizado em casa por ela.

Devido à ausência de políticas públicas, de desenvolvimento rural e de incentivo ao homem do campo que provesse os meios de manutenção da família em seu estado de origem, a família, em 1981, foi forçada a migrar para o estado do Goiás, região do "Bico do papagaio"2.

Esta nova morada localizava-se no distrito de Vila União, no município de São Sebastião do Tocantins. Nesta época, José Domingos tinha 12 anos, e foi matriculado na escola Ministro Ney Braga, na primeira série do Ensino Fundamental I, os alunos eram todos com idade elevada, o que se configura claramente na distorção idade/série, neste momento, começou-se a construir uma nova identidade cultural, assim como estabeleceu novas relações sociais a partir do contato com o grupo de colegas estudante, a qual se desenvolveu paralelamente a identidade já adquirida anteriormente que era de agricultor.

Cada cultura tem suas próprias e distintivas formas de classificar o mundo, é pela construção de sistemas classificatórios que a cultura nos propicia os meios pelos quais podemos dar sentido ao mundo social e construir significados. Há, entre os membros de uma sociedade, um certo grau de consenso sobre como classificar as coisas a fim de manter alguma ordem social. Esse sistema partilhado de significação são, na verdade, o que se entende por "cultura" (SILVA, 2020, p.42)

Nesse contexto, é natural a mistura de culturas assim como a modificação da territorialidade com a presença dos migrantes ou imigrantes, havendo alteração de quem chega com que estava no espaço, logo a rotina de agricultor foi alterada, pois durante a semana, ficava na casa da tia, localizada na vila, para frequentar a escola, no horário oposto a aula, ajudava a tia em seu pequeno comércio chamado "Secos e Molhados", nas férias escolares, seu destino era o lote da família, onde tinha a missão de ajudar o pai na agricultura, este era o seu lazer de férias.

Podemos observar que nesta época as crianças trabalhavam bastante, não havia tempo para o ócio, apenas no domingo era permitido brincar no açude, essas brincadeiras permitiu uma maior interação, que antes, no Maranhão, não existia, devido ao isolamento social que vivíamos no interior do município de Codó, pois

\footnotetext{
${ }^{2}$ Extremo norte do estado, atualmente a região pertence ao estado de Tocantins, a partir da aprovação da constituição de 1988, que criou o Estado de Tocantins, desmembrando-o do Estado de Goiás.
} 
residíamos distantes de outros grupos familiares. Essa condição social diminuía as possibilidade de interação e de troca de culturas, hábitos e valores sociais.

Em Tocantins, tínhamos uma grande expectativa em relação a continuação dos estudos, pois o ensino fundamental II ficava na escola Estadual Buriti, localizada em outra vila chamada Buriti, ou na Escola Estadual Irio Oliveira, que ficava na sede do município em São Sebastião.

As meninas, como minha irmã, eram designadas a trabalhar em casa de famílias da Vila Buriti durante o dia, para estudar a noite; já os rapazes, assim como eu, trabalhavam durante o dia na lavoura, no final da tarde, por volta das $17 \mathrm{~h} 30$ pedalavam em torno de oito quilômetros, para poderem chegar na escola e as $22 \mathrm{~h} 30$ regressavam na escuridão da noite aos seus lares.

Nestas pedalas noturnas cursei a quinta série até a metade da sétima série do ensino fundamental II, me recordo sempre de uma frase de meu pai, quando chegava às 17h: "meu filho, deixe a foice aí no roçado, que eu levo pra casa, por que essa camisa que a gente veste aqui, a juquira ${ }^{3}$ rasga, vá para a escola, que você terá a oportunidade de comprar várias camisas". Em alguns momentos, tive vontade de deixar a escola, pois a dificuldade era muita e não tinha uma visão da importância da educação, pois convivia apenas com roceiros, em um ambiente que não havia estímulo à educação.

Nesta fase, quando eu regressava à noite, jantava e em seguida fazia as tarefas da escola à luz de lamparina, pois no outro dia cedo já estaria no roçado, ajudando meu pai.

O recurso à narrativa autobiográfica inscreve-se na ideia de que, ao narrarmos episódios com significado, os analisaremos de uma forma contextualizada, tentando que essa análise ponha em evidência emoções, experiências ou pequenos fatos marcantes, dos quais antes não nos tínhamos apercebido. (FREITAS E GALVÃO, 2007, p. 2).

Analisando o passado, percebe-se que as políticas públicas minimizaram algumas situações que antes não se viam horizontes, a exemplo a chegada da luz elétrica na zona rural e os programas sociais.

A política de integração da Amazônia no final dos anos 70 e início de 80, atrelada à distribuição de terra por parte do Governo Federal, fez com que muitas pessoas do nordeste migrassem para o então Território Federal de Roraima. Meu pai,

\footnotetext{
3 Juquira: Vegetação de porte baixo ou mato que nascem predominantemente em áreas abandonadas (campos de plantio e pastos) (Fonte: $<$ https://www.dicionarioinformal.com.br >)
} 
sabendo destas novas perspectivas, resolveu, migrar para Roraima, onde já havia alguns familiares, que intercederam junto ao Governo do Território na aquisição de um lote de terra para trabalhar e prover os meios de sustento a família.

Em 1987, com ajuda financeira de parentes, migramos para o Território Federal de Roraima, para São João da Baliza, município este emancipado de Caracaraí ${ }^{4}$ em 1982, essa política de doação de lotes, na região amazônica foi instituída pelos governos militares, com o intuito de povoar a região, para evitar invasões, utilizavam o lema: "Integrar para não entregar".

Saímos de Tocantins de ônibus até Belém- PA, uma "viagem rápida" de dois dias, depois pegamos um navio em Belém, nunca tinha visto tanta água, o tamanho da embarcação era assombroso, ficamos oito dias na embarcação, junto com centenas de pessoas, o que possibilitou muitas conversas e trocas de experiências até desembarcarmos oito dias depois em Manaus.

Chegamos em Manaus em um período de inverno, a BR-174 não era asfaltada, não havia ônibus direto para Roraima, ele fazia uma linha de Manaus para a Vila de Abonari, Município de Presidente Figueiredo. Ao chegarmos nesta vila, dormimos no chão, não havia hotel, nem rede para todos os familiares, só as crianças dormiram nas redes, eu era o mais velho, não tinha rede.

Pela manhã apareceu um Mercedes vermelho carregado de vergalhões, a carga estava rente a carroceria, meu pai falou com o motorista, ele cobrou um certo preço e nos levou até a Vila Novo Paraiso, município de Caracaraí, uma viagem que durou cerca de $12 \mathrm{~h}$.

Chegando nesta vila, conseguimos, no início da noite, um caminhão que estava com destino ao Caroebe, na época, distrito de São João da Baliza, o mesmo era de um comerciante da região, meu pai novamente acertou um valor com este caminhoneiro, para que este nos levasse ao nosso destino final.

Ao chegarmos na região, já tínhamos um pequeno pedaço de terra, onde continuei trabalhando com meu pai, mas dei segmento aos estudos concluindo o ensino fundamental e médio na escola estadual Henrique Dias.

Posteriormente, na primeira metade da década de 1990, pude adquirir uma formação mais especifica através logos II, programa de formação de professores para

\footnotetext{
${ }^{4}$ Caracaraí- Distrito criado com a denominação de Caracaraí, pelo Decreto-lei Estadual n. ${ }^{\circ}$ 176, de 01-12-1938, subordinado ao município de Boa Vista. ... Elevado à categoria de município com a denominação de Caracaraí, pela Lei Federal n. ${ }^{\circ}$ 2.495, de 27-05-1955, desmembrado do município de Boa Vista.
} 
as séries iniciais, naquela época tive o privilégio de participar dentro do programa de formação, de várias oficinas pedagógicas elaboradas e orientadas pelas coordenadoras do programa, onde muitos dos cursistas já estavam em efetivo exercício da sala de aula, em escolas multiseriadas na zona rural da região. Ouvi muitos relatos pessoais dos colegas sobre as dificuldades enfrentadas por eles para ministrar aulas em condições tão adversas ao processo de ensino aprendizagem, como prolongados invernos que dificultavam o acesso a escolas multiseriadas, as vezes distante até $60 \mathrm{~km}$ da sede do município, muito professores levavam a merenda e material escolar na bicicleta, e nas escolas, suas funções eram diversas, além da docência e merendeiro ${ }^{5}$, eram responsáveis pelo prédio no que se refere a limpeza, manutenção e segurança.

Em 1993, ingressei no curso de Licenciatura Plena em História na Universidade Federal de Roraima- UFRR, o qual foi concluído em 1996, neste período de graduação, por já ter o magistério, que me habilitava a ministrar aula de primeira a quarta série ${ }^{6}$, em outubro de 1994, fui aprovado no primeiro concurso realizado pelo estado de Roraima para professor, logo a partir de 1999, na mesma escola onde estudei da sétima série até concluir o ensino médio, fui professor, coordenador pedagógico e diretor, entre o ano de 1995 a 2004.

Como coordenador pedagógico, em 1999, tive a oportunidade de fazer a primeira pós graduação, por meio de um convênio do Governo de Roraima com a Universidade Federal do amazonas- UFAM.

Em 2002, fui cedido para ministrar aula no Instituto Superior de Educação de Rorainópolis-ISER ${ }^{7}$, onde ministrei várias disciplinas, em distintas turmas, uma das mais significativas, foi a disciplina de Educação do Campo, fundamentado nos autores Sérgio Celani Leite (2002), Miguel Arroyo (1999), Bernardo Marçano Fernandes (1999), Mônica Castagna Molina(2004), Roseli Caldart(2004), entre outros, nessas discussões entrava em pauta as políticas públicas para a educação do campo, que era o principal foco e objetivo da disciplina, como na época de estudante do magistério e agora enquanto professor do Magistério Superior, muitos colegas com os quais convivi semanalmente, durante quatro anos, ainda atuavam em escolas das vicinais de São João da Baliza e dos municípios vizinhos. Foram muitas informações

\footnotetext{
${ }^{5}$ Merendeiro: Que faz a merenda, o lanche para os alunos.

${ }^{6}$ Até o ano de 2005, o ensino fundamental I era denominado série, a partir de janeiro de 2006, o Senado aprovou o Projeto de lei $n^{\circ} 144 / 2005$ que estabelece a duração mínima de 9 (nove) anos para o Ensino Fundamental, passando a ser chamado de ano, logo quarta série passou a ser denominado quinto ano.

${ }^{7}$ ISER- Instituto Superior de Educação de Rorainópolis, sua função era formação de professores do magistério superior.
} 
adquiridas com aquela experiência magnífica ao longo dos anos que modificou minha identidade.

Esse processo produz o sujeito pós- moderno, conceitualizado como não tendo uma identidade fixa, essencial ou permanente. A identidade torna-se uma "celebração móvel": formada e transformada continuamente em relação às formas pelas quais somos representados ou interpelados nos sistemas culturais que nos rodeiam [...] O sujeito assume identidades diferentes em diferentes momentos, [...] (HALL, 2020, p.12 e 13)

Por isso que enquanto aluno de mestrado em Educação busquei através do projeto de pesquisa sistematizar as informações e assim realizar uma contribuição relevante para a História da Educação do Campo daquele município, onde morei por mais de vinte anos, lá iniciei minhas atividades docentes, trabalhei com alunos que vinham de escolas da zona rural, que eram multiseriadas, convivendo com alunos e professores provenientes de escolas da zona rural, os quais já tinham uma base cultural formada e com os novos aprendizados, outros saberes foram sendo constituído a partir das relações estabelecidas no ambiente escolar.

A cultura pode ser experiência e reflexão, pensamento e sonho, paixão e poesia e uma revisão crítica e profunda de todas as certezas, convicções, teorias e crenças. Mas não pode apartar da vida real, da vida verdadeira, da vida vivida [...] (LLOSA, 2013, p.30)

Diante disso, este relato de experiência ultrapassa o aspecto do território ${ }^{8}$, pois ao longo do processo migratório, o qual fiz parte, foi se constituindo a visão da Territorialidade ${ }^{9}$ por onde passei, a mesma foi adquirida tanto no convívio familiar, quanto social, nas situações vivenciadas no ambiente escolar, embasado na formação cultural de ambos os sujeitos, agentes ativos na construção desse processo histórico.

\section{Considerações Finais}

A proposta deste estudo foi a partir do relato da trajetória de vida sob a ótica da abordagem autobiográfica, onde por meio da abordagem autobiográfica relatou-se um profundo déficit histórico/social materializado a partir das práticas hegemônicas ao

\footnotetext{
${ }^{8}$ Território é a área geográfica onde um Estado soberano exerce sua soberania, onde ele não reconhece nenhuma outra autoridade além dele.

9 Territorialidade é a ação dos agentes sobre o território, ou seja, o modo de agir em seu espaço territorial
} 
longo dos séculos, politicas essas que perpetuam a pobreza e ignorância de gerações em gerações.

Portanto, o que se percebe claramente é que as políticas públicas quando aplicada para seus devidos fins, promove um efeito positivo para a sociedade, até nos lugares mais longínquos. Possibilitando, desta forma, o crescimento intelectual do indivíduo, servindo como aporte de inclusão social.

Ao longo deste percurso vai se moldando novas identidades culturais, pois a partir da constituição de novas relações humanas, o indivíduo vai se definindo enquanto um ser social e uma educação de qualidade tem papel fundamental nesse processo constitutivo da identidade do sujeito enquanto ser social.

Conclui-se que o advento da escola na vida do indivíduo é um fator determinante de ascensão social, para o desenvolvimento humano, possibilitando ao mesmo a construção de uma visão holística ${ }^{10}$ do mundo, analisando detalhadamente os problemas pertinentes ao meio em eu vive, para assim buscar uma solução que se converta em melhoria de qualidade de vida para o sujeito e para a comunidade em que está inserido.

\section{Referências}

CLANDININ, D. Jean. CONELLY, F. Michael. Pesquisa narrativa: experiências e história na pesquisa qualitativa. Tradução: Grupo de Pesquisa Narrativa e Educação de Professores ILEEL/UFU. Uberlândia: EDUFU, 2011.

FREITAS, F. de; GALVÃO, C. 0 uso de narrativas autobiográficas no desenvolvimento profissional de professores. Ciências \& Cognição; Ano 04, vol. 12, 2007. Disponível em: Acesso em: jun. 2013

HALBW ACHS. M. Les cadres sociaux de la mémoire. Paris: Mouton, 1976

HALL, Stuart. A Identidade Cultural na Pós Modernidade, Rio de Janeiro: Lamparina, 2020.

MACHADO. Cassiano Elek (org), LLOSA, Mário Vargas, Pensar a Cultura, Porto Alegre- RS, Arquipélago Editorial, 2013.

PINEAU, Gaston; LE GRAND, Jean- Louis. As Histórias de Vida. 2o ed. Paris: PUF,1996 (Tradução: Maria da Conceição Passeggi, PPGE/UFRN, Natal, 2003. SILVA, Tomas Tadeu \& LOURO, Gracira Lopes (trad), HALL, Stuart. A Identidade Cultural na pós- Modernidade. Rio de Janeiro, Lamparina, 2020.

\footnotetext{
${ }^{10}$ A visão holística significa observar ou analisar algo ou alguma área da vida de forma global, ou seja, como um todo e não de maneira fragmentada (Fonte: 〈https://www.significados.com.br/visao-holistica〉)
} 